\title{
Permeabilidade estatal e atores privados na oferta da educação infantil: o que dizem os Planos Municipais de Educação (2014-2024)?
}

Zara Figueiredo Tripodi(@) Victor Maia Senna Delgado'(D

Érica Castilho Rodrigues'

\section{RESUMO}

Apresentam-se resultados de pesquisa que buscou mapear tendências de modos de oferta de educação infantil, na etapa creche, explicitadas em Planos Municipais de Educação (PMEs), formulados e/ou reformulados em 2015, por determinação do art. $8^{\circ}$ da lei n. 13.005/2014, que institui o Plano Nacional de Educação (PNE) para a década de 2014-2024, bem como possíveis fatores explicativos para a modalidade de oferta. Os municípios foram selecionados por amostra estratificada aleatória. Foram utilizadas técnicas de estatística descritiva, análise de conteúdo e teste do qui-quadrado de modo a analisar os dados levantados. Os elementos trazidos com o estudo apontam para a dispersão da oferta para atores situados fora do aparelho de estado, permitindo afirmar que essa lógica tende a ser uma política permanente no país, com possíveis efeitos diferentes sobre a educação, a depender da natureza jurídica da entidade parceira, uma vez que está explicitada em Planos de Estado, não de governo.

\section{PALAVRAS-CHAVE}

educação infantil; política educacional; planejamento; público-privado.

'Universidade Federal de Ouro Preto, Ouro Preto, MG, Brasil. 


\title{
PERMEABILITY OF THE STATE TO PRIVATE ACTORS IN THE PROVISION OF EARLY CHILDHOOD EDUCATION: WHAT MUNICIPAL PLANS SAY (2014-2024)?
}

\begin{abstract}
In this article we present the results of a research that sought to map the trends concerning the ways of supplying early childhood education, in the childcare stage, described in Municipal Education Plans, either formulated and/or reformulated in 2015 under the determination of Article 8, Law 13005/2014, which establishes the National Education Plan for the period from 2014 to 2024, as well as possible clarifying factors for the offer modality. The municipalities were selected through stratified random sampling. The research made use of techniques of descriptive statistics, content analysis and chi-square test to analyze the gathered data. The elements resulting from the study point out to the dispersion of the offer to actors located outside the state apparatus, allowing the statement that this reasoning tends to be a permanent policy in the country, with possible different effects on the education, reliant on the legal nature of the partner entity, since it is specified in Plans of State, not of government.
\end{abstract}

\section{KEYWORDS}

early childhood education; education policy; planning; public-private.

\section{PERMEABILIDAD ESTATAL Y ACTORES PRIVADOS EN LA OFERTA DE EDUCACIÓN INFANTIL: ¿QUÉ DICEN LOS PLANES MUNICIPALES DE EDUCACIÓN (2014-2024)?}

\section{RESUMEN}

Se presentan resultados de investigación, los cuales buscaron mapear tendencias en técnicas de oferta en educación infantil; en la etapa de cuna infantil, siendo manifestadas en Planes Municipales de Educación, formulados y/o reformulados el 2015, por determinación del Art. $8^{\circ}$ de la Ley n ${ }^{\circ}$ 13.005/2014, que constituye el Plan Nacional de Educación para la década de 20142024, así como posibles factores explicativos para la modalidad de oferta. Los municipios fueron seleccionados por muestra aleatoria estratificada. Fueron utilizadas técnicas de estadística descriptiva, análisis del contenido y test chi-cuadrado, siendo así analizados los datos reclutados dentro del estudio. Los resultados obtenidos en el presente estudio apuntan a una dispersión en la oferta de actores situados fuera del sistema de estado, permitiendo afirmar que esa lógica tiende a ser una política permanente en el país, con posibles efectos sobre la educación al depender de la naturaleza jurídica en una entidad asociada; una vez que esta es explícita en Planes de Estado y no de Gobierno.

educación infantil; política educacional; planificación; público-privado. 


\section{INTRODUÇÃO}

Em 2018, a Constituição Federal de 1988 completará três décadas de existência,e mesmo sendo considerada, por alguns especialistas, como um texto "inacabado" (Fernandes, 1989), não padece dúvidas de que a Constituição Cidadã expressa, também, o conjunto de normas que mais avançou na tentativa de construção de um estado de bem-estar social no país, se pensado em uma perspectiva histórica (Draibe, 1993; Cury, 2002; Oliveira e Adrião, 2013).Em que pese a crítica, ora pautada pelo senso comum, ora pronunciada até mesmo por sujeitos situados dentro da academia, de que, no caso brasileiro, à proclamação de direitos não tem correspondido a sua efetivação, e que, portanto, os textos legais não passariam de "letra morta", não se pode deixar de considerar o seu potencial enquanto instrumento de luta, como bem salientaram Oliveira e Adrião (2013), na medida em que, uma vez positivado o direito, existe, no caso de omissão do seu cumprimento, por parte da autoridade competente, a possibilidade de exigi-lo judicialmente.

Se é verdade que diferentes interesses e razões de Estado, bem como a ausência de um sistema nacional articulado na formulação e implementação de políticas públicas, inviabilizaram, em larga medida, a estruturação de uma integral rede de proteção social no Brasil, não é menos verdadeiro o fato de que a Constituição Cidadã enfeixou, a partir do consenso político possível, um conjunto de direitos negados à população brasileira, historicamente.

No que tange à educação, o texto constitucional de 1988 não só a instituiu, no seu art. $6^{\circ}$, como o primeiro dos direitos sociais, reconhecendo, dessa forma, o lugar privilegiado da educação na construção de estruturas intelectuais, cognitivas e socializantes necessárias ao exercício de uma cidadania ampliada, nos termos que lhe dá Cury (2008), como também avançou em muitos outros aspectos como a incorporação da educação infantil ao campo educacional, reconhecendo, assim, essa etapa como uma das garantias do dever do Estado com a educação, conforme preconiza o art. 208 da Constituição.

A introdução da fase da vida infantil na Carta Magna não se deu sob o signo do direito, mas sim sob a figura do amparo e da assistência (Cury, 1998). Na Constituição de 1891, por exemplo, o termo que vai aparecer em relação ao tema é "amparo à infância". Já no Estado Novo, a Constituição de 1937 mantém a mesma lógica da Constituição de 1891, na medida em que o texto legal dispõe que, no caso de falta de recursos para a infância, o Estado deveria providenciar "cuidados especiais", permitindo-se inferir que, uma vez mais, a lógica que subjaz é também a do cuidado e, portanto, do amparo, e não do direito da criança e dever do Estado, como lucidamente aponta Cury (1998). A Constituição de 1946, por sua vez, abriga, ao texto, a expressão “assistência”.Já em 1967, embora os termos amparo e assistência continuem presentes, será introduzida, pela primeira vez, a "noção que uma lei própria providenciará a assistência à infância"(Cury, 1998, p. 12).

Será somente com a Constituição Cidadã de 1988 que a educação infantil conquistará a "legitimidade legal atrasada em relação aos fatos" (Campos, 1998, p. 35), isso porque ganhava forças todo um movimento de pressão da sociedade civil e de outras entidades, bem como discussões, no âmbito da academia, em torno da premência de alçar a educação infantil à categoria de direito, subtraindo-a, assim, do assistencialismo que até aquele momento a havia marcado, sem um quadro legal e institucional que delimitasse os deveres e as responsabilidades aos respectivos sujei- 
tos. Assim, com a Constituição de 1988, essa fase educacional passa a ser concebida como um direito da criança pequena e dever do Estado em provê-la.

De modo a garantir as condições mínimas para se assegurar esse direito, a carta magna define, nos seus arts. 30 e 211, a competência legal prioritária dos municípios, com a cooperação técnica e financeira da União e do Estado, no âmbito da oferta da educação infantil. Do ponto de vista do financiamento, já que "direitos sociais custam e são caros" (Cury, 1998), só a partir de 2006, com a emenda constitucional n. 53/2006, que institui o Fundo de Manutenção e Desenvolvimento da Educação Básica e de Valorização dos Profissionais da Educação (FUNDEB), a educação infantil conseguiu avançar, no sentido de poder contar com um modelo de financiamento previsto em lei, via Fundo, que, minimamente, atua de modo a redistribuir os recursos dentro de um mesmo estado e, assim, lidar com parte dos desafios colocados, prioritariamente, aos municípios.

De todo modo, em que pese o significativo avanço trazido pela Constituição de 1988, não se pode desconsiderar que a agenda da educação infantil foi construída, historicamente, por uma multiplicidade de instituições e atores externos ao aparelho estatal inscritos na sua oferta, especialmente na modalidade de convênios com o poder público, o que permitiu, em larga medida, que houvesse um expressivo aumento da prestação desse direito social ao longo dessas quase três décadas (Campos, 1998; 2006).

A questão que se coloca, entretanto, à educação infantil, em termos de oferta e regulação, diz respeito ao day after à promulgação da Constituição Federal de 1988. Isso significa dizer que, mesmo garantidos um conjunto de direitos e procedimentos normativos e institucionais, a presença de um Estado apenas subsidiário e a sua substituição pela sociedade civil organizada na provisão da educação infantil, especialmente no primeiro segmento, de 0 a 3 anos, parecem não ter experimentado retração, tendo, pelo contrário, feito um movimento inverso.

O que tem havido, ao que parece, é, por um lado, o reforço na lógica de atribuir a entidades da sociedade civil a responsabilidade pela oferta de educação infantil, especialmente para as populações mais pobres. E, de outro, o aumento de instituições, de diferentes naturezas e desenho jurídico diverso, em interação com o Estado. É nesse sentido que Arelaro (2008) indaga se a política de conveniamento não teria se tornado uma política permanente de oferta de creche.

Considerando, dessa forma, que o debate em torno do atendimento à educação infantil, via convênios, especialmente no âmbito da creche, não é novo, este artigo discutirá, a partir de evidências trazidas por pesquisa de pós-doutoramento ${ }^{1}$, a tendência

1 Este trabalho é resultado de pesquisa de pós-doutoramento realizada no Centro de Estudos da Metrópole (CEM/CEPID), no Departamento de Ciências Políticas da Universidade de São Paulo (USP), sob supervisão da Profa. Dra. Marta Arretche. $\mathrm{O}$ projeto desenvolvido contou com o auxílio da Fundação de Amparo à Pesquisa do Estado de São Paulo (FAPESP), com bolsa de pós-doutorado, Projeto n 2015/14405-8.

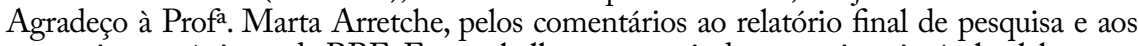
pareceristas anônimos da RBE. Este trabalho contou, ainda, com a inestimável colaboração de Rogério Barbosa (USP/CEM), Willson Gerigk (UFPR) e Gabriela Tarouco (UFPE), na sugestão de construção de banco de dados, desenho amostral da pesquisa, bem como na discussão acerca de ideologia político-partidário no Brasil. Todas as valiosas contribuições, aqui expressas, não me exime de possíveis falhas que, porventura, insistiram em permanecer. 
de intensificação da sua oferta por meio de arranjos institucionais que preveem formas de interação do Estado com entidades do chamado terceiro setor ${ }^{2}$, de institutos jurídicos diversos e, por isso mesmo, com possíveis efeitos distintos sobre as políticas educacionais.

Além desta introdução, o trabalho, em seguida, apresentará o delineamento da pesquisa, acompanhado da exposição do percurso metodológico e das opções teóricas assumidas. $\mathrm{Na}$ segunda parte, o artigo cuidará de apresentar os resultados encontrados a partir do exame da amostra de municípios selecionados e a análise desses resultados à luz da categoria analítica "permeabilidade estatal". A seção seguinte apresentará uma tentativa de explicação para os resultados encontrados pela pesquisa, a partir de testes estatísticos e revisão bibliográfica, no que tange à extensão do relacionamento do Estado com diferentes entidades situadas na sociedade civil. Por fim, o artigo aponta algumas tendências e possíveis impasses para as políticas de educação infantil, no âmbito das relações público-privadas.

\section{O PLANO NACIONAL DE EDUCAÇÃO E O DELINEAMENTO DA PESQUISA}

A aprovação do Plano Nacional de Educação (PNE) para a década 20142024, pela lei federal n. 13.005, de 24 de junho de 2014 (Brasil, 2014), em que pese o veto ao art. 21, da lei de diretrizes orçamentárias para 2018, que tratava de priorizar o orçamento necessário para se cumprir suas metas, ainda representa significativo avanço para o campo educacional, do ponto de vista do planejamento e da política pública de educação. Isso porque, em comparação a outros planejamentos decenais já construídos pelo país, esse buscou constituir-se em expressão de política de Estado, não de governo, exibindo uma ancoragem democrática mais robusta, o que reverberou, por isso mesmo, nas diretrizes, que alicerçam e sustentam o PNE. Ademais, o documento decenal buscou definir e preencher as lacunas deixadas pela Lei de Diretrizes e Bases da Educação Nacional (LDBEN), lei n. 9.394, de 1996, no tocante à gestão democrática, dando-lhe contornos mais definidos. No que tange à engenharia institucional federativa, o PNE também apresenta um significativo avanço na medida exata em que redefine o papel da União em termos de financiamento da educação, com a introdução do Custo Aluno Qualidade Inicial (CAQi) e a sua lógica redistributiva a partir da complementação financeira da União aos estados e municípios.

O PNE também trouxe, no texto legal e no seu anexo, 20 metas ambiciosas e necessárias que contam, cada uma, com um conjunto de estratégias de modo a alcançá-las, sendo a educação infantil a primeira delas. No "corpo" da meta 01 , o texto explicita a dimensão do desafio posto aos municípios: universalizar a educação

2 A despeito da confusão conceitual e da dificuldade em delimitar o que se enquadra dentro do chamado terceiro setor, no âmbito deste trabalho, adota-se a definição utilizada por Di Pietro (2015), para quem o terceiro setor é aquele composto por entidades da sociedade civil que exercem atividades de interesse público e não lucrativas. Assim sendo, neste artigo, terceiro setor refere-se a associações certificadas como entidades beneficentes ou filantrópicas, certificadas como Organizações Sociais (OSs) ou, ainda, como Organizações da Sociedade Civil de Interesse Público (OSCIPs). 
infantil, na fase pré-escolar, até 2016; e garantir que, até 2024, 50\% das crianças de 0 a 3 anos de idade tenham acesso à creche. De acordo com estudo do Instituto Brasileiro de Geografia e Estatística (IBGE) publicado em 2017, o contingente de crianças com menos de 4 anos de idade não matriculadas em creche corresponde a 7,7 milhões, sendo que, desse grupo, 4,7 milhões estão fora de uma unidade de educação infantil por não haver vagas, haja vista que há desejo do responsável pela criança na matrícula (IBGE, 2017).

Tendo em vista esse cenário, delineado, de um lado, pela aprovação do PNE e pelas possibilidades de superação dos impasses do financiamento educacional, e, de outro, pelas metas arrojadas estipuladas para a educação infantil, especialmente na fase creche, a pesquisa buscou mapear tendências de modos de oferta da oferta de educação infantil, na etapa de creche, explicitadas nos Planos Municipais de Educação (PMEs), formulados e/ou reformulados em 2015, por determinação do art. $8^{\circ}$ da lei n. 13.005/2014, de modo a compreender a extensão da "permeabilidade" do Estado (Cardoso, 1975; Marques, 1999; 2000) a atores situados na sociedade civil e que compõem o chamado terceiro setor ou o público não estatal (MARE, 1995). Com relação a essa primeira questão, objetivou-se, ainda, identificar possíveis fatores explicativos das escolhas feitas pelos municípios e explicitadas pelos PMEs (2014-2024), em termos de modos de oferta.

Partiu-se da hipótese de que os municípios tenderiam a intensificar a governança educacional (Rhodes, 1996; Diniz, 1996; Melo, 1996; Kooiman, 2003) na etapa creche, entendida, aqui, como uma dispersão de oferta para atores situados na sociedade civil organizada, com diferentes desenhos e institutos jurídicos, movidos por, pelo menos, três fatores:

1. desequilíbrio do federalismo fiscal, já que à responsabilidade das matrículas da educação infantil pelo ente municipal não correspondeu uma transferência de recursos equivalente por parte da União ou dos estados;

2. a natureza arrojada das metas da educação infantil destinadas aos municípios, num contexto em que maioria deles possui baixa capacidade fiscal, tributária e institucional para formular e implementar políticas para essa fase escolar; e

3. reconhecimento da oferta de vagas em creche como forma de legitimação de governos municipais.

\section{QUESTÃO DE MÉTODO}

Em termos metodológicos, o desenho da pesquisa, de natureza exploratória, privilegiou a abordagem qualitativa, para mapear as lógicas de oferta de educação infantil explicitadas em 169 PMEs, e utilizou-se, para isso, de um conjunto de procedimentos como:

- pesquisa documental de fontes primárias, ou seja, leis sancionadas por cada ente municipal;

- pesquisa bibliográfica e teste estatístico para testar hipóteses levantadas; e

- análise de conteúdo realizada por meio do software atlas.ti e reexaminada utilizando a técnica de Bardin (2009). 
Os PMEs foram selecionados a partir de uma amostra estatística estratificada aleatória de municípios, produzida a partir da observação de quatro variáveis:

- gasto per capita do município;

- população total do município;

- Produto Interno Bruto (PIB) per capita; e iv) capacidade estatal.

A amostra foi gerada pelo software $\mathrm{R}$, no qual foram submetidas as seguintes bases de dados:

- dados sobre gastos dos municípios, segundo as Finanças do Brasil (FINBRA) correspondentes ao ano de $2012^{3}$;

- PIB per capita dos municípios, segundo o IBGE, correspondente ao ano de 2011;

- população do município, segundo IBGE, do ano de 2011; e iv) capacidade estatal, segundo a Pesquisa de Informações Básicas Municipais (MUNIC) do IBGE, correspondente a 2014.

À amostra gerada, foram acrescentadas todas as capitais brasileiras. Em seguida, os PMEs relativos à amostra foram categorizados, utilizando software atlas. ti, e submetidos à análise de conteúdo, utilizando a técnica desenvolvida por Bardin (2009). As razões levantadas de modo a sustentar ou refutar a hipótese de que haveria uma dispersão da oferta de creche por atores não estatais foram testadas por meio de testes estatísticos.

\section{PERCURSO TEÓRICO-ANALÍTICO}

Reconhecendo que mudanças em concepções de Estado alteram não só desenhos institucionais, mas exigem, também, no campo da pesquisa, novas ferramentas teórico-analíticas, a discussão aqui proposta, embora se filie a outros trabalhos que vêm sendo desenvolvidos nos Brasil, no âmbito das relações entre público e privado na educação, toma como decisão analítica preliminar a noção de "permeabilidade" do Estado como categoria de análise (Cardoso, 1975; Marques, 1999; 2000), em detrimento de privatização.

Parte-se do pressuposto de que a discussão de lógicas privatizantes da educação no Brasil não prescinde de um instrumental teórico-analítico que dê conta de examinar outras relações de causalidade implicadas na escolha do setor privado no modo de oferta educacional, para além do aspecto econômico ou fiscal.

A noção de "permeabilidade" aparece na literatura nos anos de 1970, em texto escrito pelo sociólogo Fernando Henrique Cardoso, no qual examina os "aspectos políticos do planejamento" no Brasil, chamando a atenção para a existência de "círculos de interesse organizados em anéis" na produção de políticas. Segundo Cardoso (1975),

3 A variável "gasto dos municípios" utilizada foi organizada por Davoud Taghawi-Nejad, pesquisador de pós-doutorado do Centro de Estudos da Metrópole CEM/CEPID, a partir de dados das FINBRA. 
"os interesses privatistas brasileiros fluem, em suas relações com o Estado, através de teias de cumplicidades pessoais", de natureza difusa, "mais orientada para relações e lealdades pessoais que tornavam cúmplices desde o vereador, o deputado, o funcionário de uma repartição fiscal, o industrial, comerciante ou banqueiro, até o ministro, quando não o próprio presidente", do que necessariamente, de lobbies, haja vista que estes supõem "alto grau de organização dos grupos interessados numa decisão e racionalidade na definição de objetivos e meios" (Cardoso, 1975, p. 179).

No final dos anos de 1990, os trabalhos desenvolvidos por Marques (1999) levaram a que essa chave interpretativa passasse a ter mais presença na análise de políticas públicas. Para o autor, a noção de permeabilidade pode ser entendida como:

uma forma similar à descrita pelas categorias de anéis burocráticos, lobby, e privatização do Estado. Embora a idéia geral dos conceitos seja assemelhada, sua especificação deixa clara inúmeras diferenças. A permeabilidade é produzida a partir de uma teia de relações e cumplicidades, construída ao longo da vida dos indivíduos, incorporando diferentes tipos de elo. Ao contrário do que seria de se prever pela utilização direta de uma perspectiva baseada no lobby, por exemplo, o dinheiro é apenas um dos tipos de vínculos lançados entre indivíduos e grupos. (Marques, 2000, p. 53)

A definição construída por Marques (2000) aponta para, pelo menos, dois importantes aspectos da análise de políticas públicas. O primeiro deles relaciona-se aos efeitos decorrentes do encontro ou da superposição do Estado com o privado. Tais efeitos podem assumir contornos diferenciados a depender do padrão relacional que se institui em determinado momento, sob certas condições históricas, sociopolíticas e econômicas. Dito de outro modo, as políticas educacionais ofertadas por atores privados podem apresentar desenhos e lógicas diferentes de oferta, a depender de qual ator está em interação com o Estado. Ou seja, a política de oferta de educação infantil efetivada por uma OS pode apresentar feição e efeitos diferentes sobre os processos educacionais, se ofertada por uma OSCIPs, por exemplo.

Já o segundo aspecto diz respeito ao potencial da noção de "permeabilidade" na busca de possíveis fatores explicativos de determinada opção política. Isso porque a permeabilidade é "perene no tempo e presente em todos os campos de ação do Estado" (Marques, 2006, p. 33) e, portanto, a sua potencialidade se realiza (ou não) em termos das condições materiais concretas postas aos formuladores de políticas, das concepções de Estado assumidas por determinado grupo que detém o governo por certo período, em termos de definição das funções do Estado diante da sociedade, da dependência de trajetória de certas políticas, além da própria dinâmica de acumulação do capital na contemporaneidade e do jogo político dentro de uma democracia. Com isso se quer dizer que essa categoria permite, em termos analíticos, promover o debate das relações público-privadas na educação sob uma perspectiva plural que envolve o reconhecimento de que o Estado é permeável a atores e interesses externos, em maior ou menor grau, em momentos diferentes do tempo, em decorrência de fatores históricos, econômicos, políticos e, até mesmo, motivado por razões estritamente pessoais. 
No caso da oferta de matrículas em creche, por exemplo, as relações público-privadas têm sido explicadas em termos de fatores de ordem econômica; ou seja, em boa parte das análises, evoca-se a condição tributária e fiscal dos municípios, reconhecidamente frágil, como razão explicativa para a dispersão de oferta para o terceiro setor. Entretanto, adotar apenas essa condicionante parece menosprezar outros importantes fatores como aqueles de natureza política.

Nesse sentido, a noção de permeabilidade parece ser uma melhor ferramenta analítica, em relação à noção de privatização, de modo a dar conta de diferentes arranjos institucionais que têm sido utilizados pelos governos nacionais.

\section{EDUCAÇÃO INFANTIL E POLÍTICA EDUCACIONAL}

Investigar modos de oferta de educação infantil, na etapa creche, assim como possíveis fatores explicativos para escolhas de provisão, exige que se tome em conta, pelo menos, dois aspectos: de um lado, a redefinição do padrão de relações intergovernamentais, com o novo papel assumido pelos municípios, a partir da Constituição de 1988 e a ascensão da educação infantil como direito reconhecido constitucionalmente. De outro, o movimento de reforma do Estado que começa a se desenhar no Brasil, a partir dos anos de 1990, e que vai assumir contornos mais definidos com o Plano Diretor de Reforma do Aparelho do Estado (PDRAE), que, por sua vez, elabora o marco conceitual e cria as condições legais para a construção da propriedade público não-estatal, apontando, já àquela altura, para a sociedade civil organizada como suposta alternativa da dicotomia Estado-Mercado.

Do ponto de vista da engenharia institucional federalista, a aposta na descentralização como instrumento de promoção da eficiência dos serviços, da redução de níveis de corrupção e da implementação de uma agenda democratizante no país (Arretche, 1996) levou a que o país assumisse um sistema triplo, concedendo, assim, aos municípios o status de ente federado autônomo. A nova condição federativa foi acompanhada de aumento significativo de responsabilidades, como a prioridade sobre a educação infantil, sem, contudo, ter havido uma consequente transferência de recursos ou reforma tributária, de modo a lhes fazer face, em um contexto de baixa capacidade fiscal e tributária.

De par com a descentralização, a proliferação de ideias em torno da reordenação do lugar do Estado na oferta dos serviços públicos e a subsequente introdução da figura da propriedade público não estatal no cenário das políticas públicas de corte social ganhou força e adeptos. Na perspectiva de sedimentar essa nova esfera de entrega de bens públicos, a gestão do então presidente Fernando Henrique Cardoso (1995-2002), contando com uma expressiva base de apoio político parlamentar, viu aprovados dois dispositivos legais que vão assumir cabal importância na reordenação do papel do Estado: a lei n. 9.637, de 1998 (Brasil, 1998), que dispõe sobre qualificação de entidades da sociedade civil como OSs, e a lei n. 9.790, de 1999 (Brasil, 1999), que trata da qualificação de pessoas jurídicas de direito privado, sem fins lucrativos, como OSCIPs.

Embora a extinção do MARE, no segundo mandato do presidente Fernando Henrique Cardoso (1999-2002), tenha impedido a mobilização das alianças e esforços necessários para a efetivação de muitas propostas idealizadas e positivadas, no âmbito federal, as ideias ali desenvolvidas sobre o setor público não estatal passaram a ser 
disseminadas entre os entes estaduais, impulsionadas, principalmente, por comunidades de políticas (Massardier, 2006), formadas a partir da migração de burocratas, que compuseram o alto escalão do governo central, para os estados brasileiros.

A partir de 2003, principalmente, a transferência desses burocratas viabiliza a formação de coalizões de atores que passam a intermediar, nos governos subnacionais, interesses antes construídos no âmbito federal, como a disseminação do terceiro setor, especialmente nos formatos de OSs e OSCIPs, como opção à oferta de políticas públicas de corte social, como a educação.

Nesse sentido, os entes federados passam a criar seus próprios desenhos legais, alguns em estreito alinhamento com os instrumentos jurídicos federais, outros com contornos próprios. Esse movimento levou a que se chegasse, em 2017, com 25 estados brasileiros e o Distrito Federal já com marcos legais próprios para a qualificação de OSs. No caso das OSCIPs, 11 estados possuem, também, leis próprias, conforme se pode ler na Figura 1.

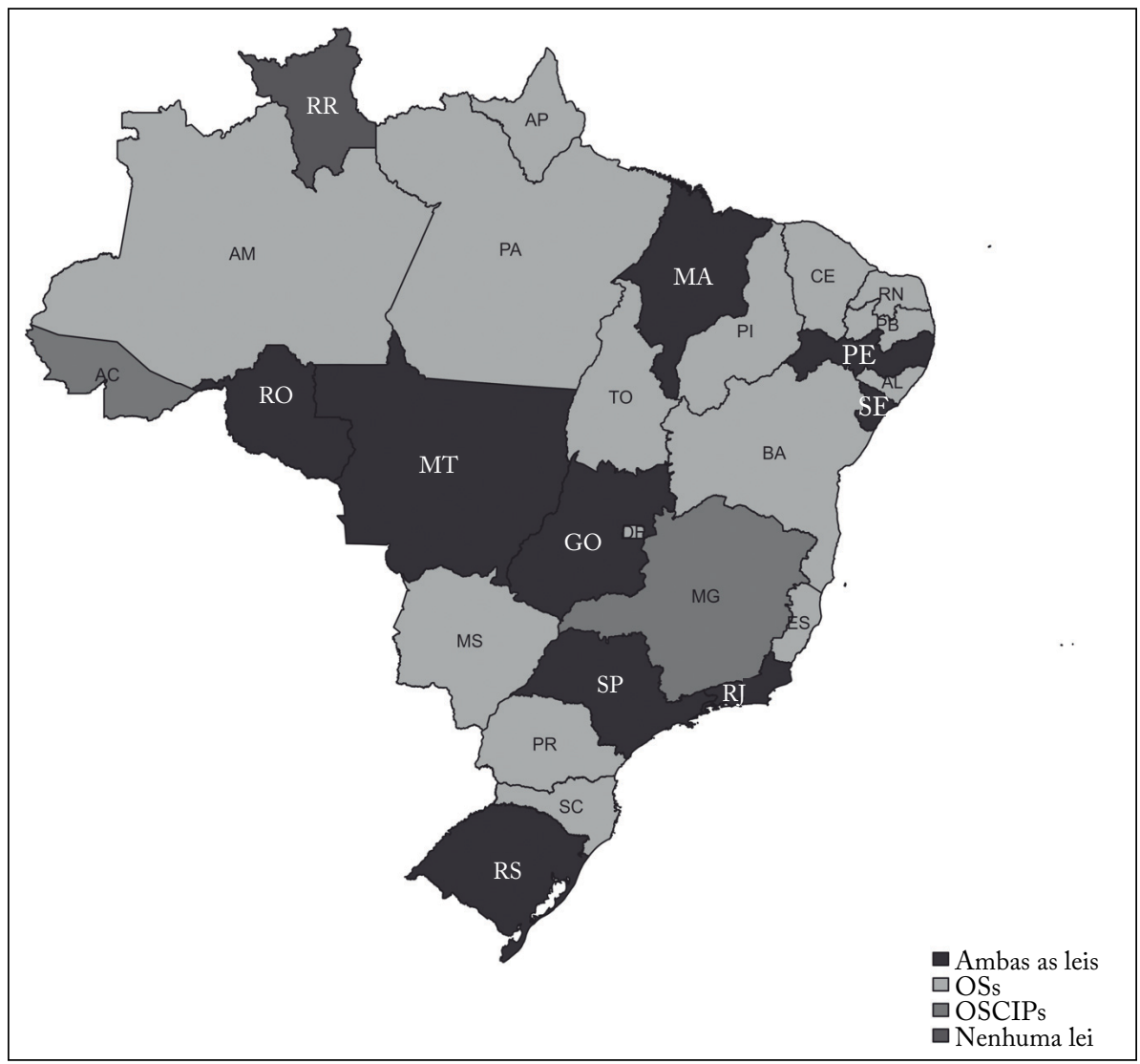

Figura 1 - Distribuição de Organizações Sociais e Organizações da Sociedade Civil de Interesse Público nos estados brasileiros (2017).

Fonte: Tripodi (2016).

Elaboração própria.

OSs: Organizações Sociais; OSCIPs: Organizações da Sociedade Civil de Interesse Público. 
A leitura da Figura 1 dá-nos conta de que as OSs estão mais presentes nos estados do que as OSCIPs, o que sugere que as mudanças que podem derivar dessa relação entre público e privado tem potencial para redefinir, de modo definitivo, as fronteiras entre Estado e sociedade, uma vez que a interação com OSs, diferentemente de OSCIPs, pode se configurar como transferência de serviços sociais para o terceiro setor, com extinção da esfera estatal que ofertava a atividade, ao contrário das OSCIPs, cujas atividades assumidas caracterizam-se como atividade de fomento. Os municípios, embora não com a agilidade dos estados, têm aprovado, também, suas leis próprias, de modo a qualificar entidades do terceiro setor.

Assim, se há o desejo de examinar as tendências e lógicas de oferta de educação infantil, é imprescindível que se tome essas duas tendências em conjunto: primeiro, a descentralização de 1988, com a consequente atribuição de responsabilidades da educação infantil para os municípios. Segundo, a substituição do Estado pela sociedade, no formato de parcerias com o terceiro setor, de modo a expandir o sistema.

$\mathrm{O}$ que parece resultar do encontro dessas duas tendências pode ser respondido em termos de uma quase aporia. A educação infantil, historicamente, é tida como uma concessão e ofertada pela assistência social, o que leva, em larga medida, à própria expansão do sistema. A posterior incorporação à política educacional insere a educação infantil na perspectiva do direito; entretanto, a ausência de um regime de colaboração bem definido e as concepções de Estado que passam a viger logo após o reconhecimento do direito, faz com que as condições estruturais para a oferta dessa etapa educacional não se alterem de modo significativo, levando-se a que a expansão continue a ser efetivada por meio de um conjunto de diferentes atores, situados, ainda, na esfera societal.

A lei federal n. 13.005/2014, que aprova o PNE (2014-2024), ao estipular as metas para a educação infantil, o faz para cada um dos municípios do país, em decorrência do preceituado no seu art. $8^{\circ}$. Ao mesmo tempo, entretanto, que prevê metas ambiciosas para as municipalidades, a mesma lei redesenha a engenharia federativa à medida que prevê a criação de um Sistema Nacional de Educação e de arenas intergovernamentais permanentes de negociação, pactuação e cooperação $\left(\S 5^{\circ}\right.$, art. $\left.7^{\circ}\right)$, positiva a adoção de arranjos de desenvolvimento da educação, via fortalecimento do regime de colaboração entre os municípios $\left(\S 7^{\circ}\right.$, art. $\left.7^{\circ}\right)$ e, consequentemente, prevê um progressivo investimento público em educação, para além da vinculação de recursos manifesta no art. 212, da Constituição, de modo a fazer face às necessidades financeiras decorrentes do cumprimento das metas. ( $\S \S 3^{\circ}, 4^{\circ}$ e $5^{\circ}$, art. $5^{\circ}$ ). Ademais, o financiamento da educação passa a contar com uma meta específica no PNE, a de número 20, com o índice CAQi.

Nota-se, pois, que o PNE, como expressão de uma política de Estado, aprovou as condições necessárias para que suas metas pudessem ser cumpridas. Entende-se, portanto, que as municipalidades, ao formularem seus documentos próprios, tinham como diretrizes todas essas dimensões apresentadas, sobretudo a de ordem financeira, até mesmo porque os planos decenais deveriam ser alinhados ao nacional, por força da lei. É nesse sentido, portanto, que se faz importante mapear e compreender como os municípios explicitaram em seus planos decenais o modo de oferta da educação infantil. 
O fato de a lei n. 13.005/2015 haver aprovado uma dinâmica federativa que contempla uma redistribuição de recursos mais equânime e uma base de cooperação intergovernamental mais definida teria levado os municípios a optarem pela oferta estatal da educação infantil ou haveria uma dependência de trajetória (path dependence) que vem marcando essa etapa, baseada na hibridez de atores inseridos na sua oferta? E, ainda, em caso de expansão da oferta pela sociedade civil organizada, quais as possíveis razões explicativas desse processo? É sobre essas questões que a seção seguinte se debruçará, a partir da análise dos PMEs.

\section{PÚBLICO OU PRIVADO: O QUE DIZEM OS PLANOS MUNICIPAIS DE EDUCAÇÃO?}

Os municípios cujos planos decenais foram examinados resultam, como já discutido na seção dedicada à metodologia, de uma amostra estratificada aleatória, à qual foram acrescidos todos os municípios capitais, resultando em um universo de 169 municipalidades.

A análise dos PMEs e do Plano Distrital de Educação (PDE) permite afirmar, de um lado, que a permeabilidade do governo local a atores situados na sociedade civil pode ser observada em todas as regiões brasileiras, sem haver um nicho geográfico no qual ela se concentre; de outro, que essa tendência apresenta contornos diferentes entre as municipalidades examinadas. Assim sendo, 73 municípios, de um total de 169, explicitaram nos seus PMEs que a expansão da oferta da educação infantil, na etapa creche, irá se efetivar, de modo a cumprir a meta estipulada pelo $\mathrm{PNE}$, em interação com entidades do chamado terceiro setor, conforme se pode depreender da leitura da Tabela 1.

Tabela 1 - Distribuição de oferta da educação infantil, por ator estatal e não estatal, por região (2015).

\begin{tabular}{l|c|c|c|c}
\hline \multirow{2}{*}{ Região } & \multicolumn{4}{c}{$\begin{array}{c}\text { Brasil } \\
\text { infantil puição de oferta da educação }\end{array}$} \\
\cline { 2 - 5 } & $\begin{array}{c}\text { Oferta por meio de interação } \\
\text { com o terceiro setor }\end{array}$ & $\begin{array}{c}\text { Oferta } \\
\text { estatal }\end{array}$ & $\begin{array}{c}\text { Não } \\
\text { informado }\end{array}$ & Total \\
\hline Centro-Oeste & 10 & 10 & 0 & 20 \\
\hline Nordeste & 21 & 27 & 3 & 51 \\
\hline Norte & 9 & 8 & 0 & 17 \\
\hline Sudeste & 18 & 20 & 12 & 50 \\
\hline Sul & 15 & 80 & 16 & 31 \\
\hline Total & 73 & & 169 \\
\hline
\end{tabular}

Fonte: Planos Municipais e Distrital de Educação.

Elaboração própria. 
Um dos primeiros aspectos a serem considerados é a multiplicidade de atores do terceiro setor com os quais os municípios explicitaram intenção de firmar parcerias. Embora o termo "convênio" ainda seja uma das expressões mais recorrentes nos documentos, em referência à leis n. 8.666, de 1993, e à lei n. 12.101, de 2009, um conjunto de municípios estabeleceu nos seus documentos que pretende estabelecer parcerias, também, com entidades privadas com fins lucrativos, além de OSs e OSCIPs.

Sobre a preponderância do instrumento "convênio", explicitado nos PMEs, há, pelo menos, duas questões a se observar. Uma delas é que essa preferência pode ser resultado de uma dependência de trajetória, haja vista que foi a modalidade de parceria mais recorrente ao longo da expansão da educação infantil. A outra questão relaciona ao próprio instituto jurídico que terá que ser alterado nesses PMEs, haja vista que a lei n. 13.019/2014, aprovada um mês após a lei n. 13.005/2014 e conhecida como o marco legal do terceiro setor, exclui o instrumento "convênio" das parcerias firmadas entre poder público e entidades da sociedade civil, substituindo-o pelas figuras jurídicas do "Termo de Cooperação" e Termo de Fomento". O "convênio" passa a ser um instrumento jurídico exequível apenas para a formalização de parcerias entre entes federados, como determina o $\S$ único, do art. 84, da referida lei.

Um aspecto intimamente vinculado àquele anterior tem a ver com a distribuição de ocorrências entre capitais e municípios. Das 25 capitais $^{4}$ e do Distrito Federal, 7 municípios não explicitaram, em seus PMEs, a intenção de interagir com o terceiro setor na oferta de creche. Quatro deles encontram-se no Norte: Boa Vista (RR), Porto Velho (RO), Boa Vista (TO) e Belém (PA). Além desses, Porto Alegre (RS), Vitória (ES) e Fortaleza (CE) também seguiram na mesma direção dos nortistas.

$\mathrm{O}$ município de Belém (PA), além de não especificar intenção em firmar parcerias com atores societais, explicita o propósito de "extinguir os convênios de subvenção social, substituindo-os progressivamente por prédios próprios e adequados ao atendimento da Educação Infantil, absorvendo $100 \%$ da demanda oriunda dos mesmos, até o final do plano vigente" (Belém, 2015, p. 23). A meta da municipalidade manteve-se alinhada à nacional, ou seja, busca-se atender a $50 \% \mathrm{da}$ população em idade de creche até 2024 , o que representa, no âmbito do município, expandir a oferta em 22,8\%, isto é, dobrar o atendimento que, em 2013, era de 22,2\%.

Tendo como cenário a região Norte, no polo exposto, em termos de formas de oferta, está o município de Rio Branco (AC), cujo plano esclarece que a meta 01, etapa creche, será alcançada por meio de parcerias, também, com OSs.

Quando se toma o restante das capitais como objeto de análise, algumas delas chamam a atenção, no que se refere aos locais de governança, ou seja, aos modos de oferta em parceria, manifestos nos planos. Ainda que a maioria delas aponte a interação do Estado com o público não estatal, entes federados como

4 O município do Rio de Janeiro, até o fechamento deste trabalho (setembro de 2017), não havia aprovado seu PME. 
Distrito Federal e Belo Horizonte, por exemplo, apresentam, do ponto de vista documental, uma tendência mais consolidada de a educação infantil se efetivar via terceiro setor.

No Plano de Educação do Distrito Federal, essa tendência está sugerida na própria estrutura do documento. Ele expande a meta de oferta de creche para $60 \%$, dos quais $90 \%$ se dará em tempo integral e estabelece, já no texto relativo à meta, a forma de sua efetivação. Nesse caso, portanto, a opção de interação com o terceiro setor já se constitui como uma META do plano:

META: Universalizar, até 2016, a educação infantil na pré-escola para as crianças de 4 a 5 anos de idade e ampliar a oferta de educação infantil em creches públicas e conveniadas, de forma a atender no mínimo $60 \%$ da população dessa faixa etária, sendo no mínimo $5 \%$ a cada ano até a final de vigência deste Plano Distrital de Educação - PDE, e ao menos 90\% em período integral. (Distrito Federal, 2015)

A opção de modo de oferta é ratificada na estratégia n. 02, na qual se reafirma que o ente federado irá " 1.2 - Admitir, até o fim deste PDE, o financiamento público das matrículas em creches e pré-escolas comunitárias, confessionais ou filantrópicas, sem fins lucrativos, conveniadas com o poder público" (Distrito Federal, 2015).

Um ano após a aprovação do PDE, o governador Rodrigo Rollemberg, do Partido Socialista Brasileiro (PSB), anunciou a intenção de expansão da educação infantil via voucher. Em junho de 2016, foi encaminhado à Câmara Legislativa o Projeto de lei n. 1.177/2016, de iniciativa do Executivo, que instituiu o Programa Bolsa Educação Infantil - Pré-escola, destinado ao atendimento de crianças na faixa etária de 4 a 5 anos.

O seu art. $5^{\circ}$, ao tratar da modalidade de auxílio, dispõe que a Bolsa Educação Infantil - Pré-escola prevista na lei seja "paga diretamente à instituição educacional parceira”, sendo $\mathrm{R} \$ 456,57$ o valor mensal da bolsa por beneficiário, conforme expresso no $\S$ único do art. $6^{\circ}$.

No caso do Distrito Federal, entretanto, o padrão relacional efetiva-se no formato "Termo de Cooperação", amparado, portanto, pela lei n. 13.019/2014, que prevê tal instituto em substituição à modalidade "convênio", extinta na modalidade de parceria entre Estado e sociedade civil. Nesse formato, a interação entre esses atores se efetiva como atividade de fomento, continuando a regulação educacional, no plano legal, sob a responsabilidade do Estado.

Belo Horizonte (MG), por sua vez, parece considerar as parcerias entre Estado e sociedade civil como uma política permanente de oferta de educação infantil. É esse sentido que as estratégias 1.1,1.12 e 1.13 do PME da capital mineira deixam entrever:

1.1) definir, em regime de colaboração com a União, o estado e entidades da sociedade civil, metas que assegurem a expansão na rede pública de educação infantil de zero a cinco anos, segundo parâmetro nacional de qualidade e considerando as peculiaridades do Município; [...] 
1.9) criar um sistema de inscrições, disponível na internet, para a rede de instituições parceiras, visando aprimorar o levantamento de demanda manifesta na cidade; [...]

1.12) realizar, periodicamente, chamamento público para a inclusão de novas instituições privadas comunitárias, filantrópicas ou confessionais para atendimento à educação infantil; [...] (Belo Horizonte, 2016)

O primeiro elemento que permite fazer a afirmação é o próprio acréscimo da sociedade civil como elemento estruturante do regime de colaboração proposto: "o regime de colaboração se dará com a União, Estado e entidades da sociedade civil” (Belo Horizonte, 2016, p. 02).

O segundo elemento é a decisão de criar um sistema de inscrições para a rede de instituições "parceiras". Nesse caso, subentende-se que, ao se criar esse sistema e ao vinculá-lo ao levantamento de demanda manifesta, essas entidades se constituirão em um centro aberto para oferta de vagas tão logo haja manifestação de interesse por parte da comunidade. Por fim, a estratégia 1.12, ao prever um processo "periódico" de chamamento para inclusão de novas instituições da sociedade civil, está apontando para um movimento mais ou menos constante para essa ação.

Ainda na seara dos municípios capitais, cabe sublinhar os casos de São Paulo (SP) e Vitória (ES). O primeiro chama a atenção para o processo dinâmico de produção de políticas públicas e de seu conteúdo substancial, resultante, em larga medida, da capacidade que atores políticos e/ou sociais têm de influenciar e agir sobre determinada agenda, levando à adoção de determinada medida ou ação, em detrimento de outra.

O projeto de lei enviado ao legislativo paulista, em um dos Substitutivos, recebeu redação para a meta relacionada à educação infantil em que se manifestava o objetivo de ampliação da oferta via rede municipal direta:

META. Universalizar, até 2016, a Educação Infantil para as crianças de 4 (quatro) a 5 (cinco) anos de idade e ampliar a oferta de Educação Infantil na rede municipal direta de forma a atender toda a demanda efetiva da população de zero até 3 anos e 11 meses no prazo de cinco anos. (São Paulo, 2014)

Tal proposição é reafirmada em seguida, nas estratégias 5.2. e 5.3, nas quais o município trata de especificar a data limite para finalizar o atendimento via parceria com o terceiro setor, além de explicitar o intento de incorporar à rede pública as iniciativas privadas:

5.2. Investir em unidades públicas de Educação Infantil diretas, limitando-se o atendimento na rede conveniada, desde que assegurados os padrões de qualidade definidos pelo município, às matrículas realizadas até 2014;

5.3. Realizar processo de reincorporação dos Centros de Educação Infantil indiretos para responsabilidade direta da Secretaria Municipal de Educação, de forma gradativa no prazo de cinco anos; [...]. (São Paulo, 2014) 
Entretanto, tal proposição não contou com o apoio político necessário para fazê-la prevalecer, levando a que novo Substitutivo, o de n. 02, fosse apresentado e aprovado. Nele, prevalece a ideia de que o sentido de público está mais relacionado à gratuidade do serviço prestado do que ao ator responsável pela oferta; portanto, público não significaria, necessariamente, estatal. A tentativa de reverter a situação foi levar para o Plenário emendas. Contudo, todas elas, no que tange ao modo de oferta somente por ator estatal, foram rejeitadas, levando-se ao seguinte texto final para a meta referente à educação infantil:

\section{META 5.}

Universalizar, até 2016, a Educação Infantil para as crianças de 4 (quatro) e 5 (cinco) anos de idade e assegurar, durante a vigência do Plano, atendimento para $75 \%$ das crianças de zero a 3 anos e 11 meses ou $100 \%$ da demanda registrada, o que for maior. Estratégias:

5.1. Investir na ampliação da oferta de educação infantil de 0 (zero) a 3 (três) anos na rede direta, indireta e conveniada, assegurando sua qualidade. (São Paulo, 2015)

Nota-se que a meta foi alterada, na medida em que é retirada do corpo do texto a menção à "rede municipal direta" e a primeira estratégia (5.1) complementa o novo texto ao expressar que as modalidades em que se pautarão a oferta de creche: direta, indireta e conveniada.

Já a capital do Espírito Santo construiu tanto a meta do PME quanto as estratégias, alicerçadas no regime de colaboração. Já na meta 01 estão bem equacionados os pressupostos que fundamentarão a oferta de creche, cujo percentual de atendimento é expandido para 100\% da demanda manifesta, divergindo do PNE. As estratégias, por sua vez, não sinalizam para parcerias com a sociedade civil, valendo-se, em todas as 19 ações, de formas de cooperação entre União, estados e municípios.

Saindo das capitais, municípios como Santa Bárbara D'Oeste (SP) ou Turmalina (MG) expressam a intenção de firmar parcerias com o terceiro setor, mas também com entidades privadas com fins lucrativos.

Outra dimensão que importa destacar diz respeito à estruturação de PMEs elaborados por capitais e demais municípios. Nos documentos decenais dos primeiros, há uma preocupação maior, na maioria dos casos, em manter a meta alinhada à nacional, ou seja, não expandir para além de em $50 \%$ de oferta até 2024. Além disso, os textos deixam claro que todas as estratégias desenhadas de modo a atingir a meta serão efetivadas por meio de regime de colaboração entre União, Estado e municípios. Apenas o município de São Paulo previu, no aspecto orçamentário, o aumento do percentual de vinculação de impostos para a educação, a ser inserido na lei orgânica. Outros, como Teresina (PI) e Fortaleza (CE), explicitaram, já na meta 01 , a implementação do índice CAQi como possibilidade para fazer face às metas propostas pelo PME.

Já os PMEs dos demais municípios não contemplaram a questão tributária e fiscal ao tratar das metas e respectivas estratégias. Nesse sentido, não foi incomum encontrar aqueles que expandiram suas metas de creche sem apresentar, no entanto, ações que viabilizariam o seu alcance. Em casos como esses, nem o regime de colaboração nem 
a parceria com a sociedade civil foram mencionados. Além disso, se considerado em relação às capitais, o número de estratégias é sensivelmente maior. Enquanto naqueles a média é de 22 estratégias para a meta 01, nesses o número cai para 13.

Dentre eles, chama a atenção casos como de Fronteira dos Vales (MG), Dores do Indaiá (MG) e Maripá de Minas (MG). Neles, há uma expansão da meta para 70, 80 e 60\%, respectivamente. Contudo, nas cinco estratégias que desenvolvem, não apresentam o modo como essa meta será atingida, não fazem menção a regime de colaboração ou parcerias com entidades da sociedade civil. Questiona-se mesmo, no âmbito deste trabalho, se é possível entender tais documentos como expressão de políticas de Estado, tendo em conta a fragilidade em sua construção.

\section{SOMENTE O FINANCIAMENTO IMPORTA?}

Os dados trazidos pela análise dos PMEs confirmaram a hipótese de trabalho de que haveria uma tendência de dispersão de oferta de creche, enquanto intenção explicitada pelos municípios. Assim, buscou-se compreender as possíveis razões explicativas para tal escolha, tendo em vista que o PNE tentou estabelecer uma nova dinâmica federativa, no que tange ao regime de colaboração. Ademais, a criação do índice CAQi e o aumento do percentual do PIB destinado à educação, aprovados pelo PNE, permitiriam, em certa medida, que os municípios pudessem assumir a expansão do sistema por oferta direta; entretanto, não o fizeram. Ao contrário, cuidaram de criar estratégias que colocassem o terceiro setor como ator privilegiado nesse processo. Assim sendo, a questão que se coloca é: o financiamento é uma variável determinante para a escolha dos municípios, em termos de oferta da educação infantil? Não haveria, no caso da oferta de matrículas em creches, no Brasil, uma dependência de trajetória herdada da sua vinculação à assistência social, cuja oferta se dava, sobretudo, por entidades beneficentes? Ou a opção de modo de oferta, explicitada nos PMEs, estaria relacionada à ideologia partidária?

O caso de São Paulo (SP), em alguma extensão, não teria potencial para tensionar a variável "financiamento" como única dimensão explicativa? A linha de raciocínio que subjaz ao argumento é simples. A capital paulista possui uma significativa capacidade tributária e fiscal, embora tenha, também, uma alta demanda reprimida por creche. Na vertente do financiamento educacional, o município tem um dos valores aluno/ano mais altos do país, chegando a alcançar aquele proposto pelo índice $\mathrm{CAQ}$, em muitas etapas e modalidades educacionais. Teoricamente, essa condição poderia viabilizar a expansão de oferta de vagas em creche de modo direto, ou seja, via Estado. Aceitando-se, portanto, esse raciocínio, a questão do financiamento, ainda que não possa ser minimizada como importante variável explicativa, permite que se examine outras possíveis razões, de forma a se compreender a "permeabilidade" do Estado a atores societais.

Para explorar esse problema, o artigo buscou testar algumas hipóteses sobre as possíveis razões que levariam à dispersão da oferta de creche para o terceiro setor. Para tanto, utilizaram-se testes estatísticos e revisão de literatura. Assumiu-se a dispersão de oferta de vagas em creches como variável dependente e buscaram-se possíveis razões explicativas a partir de variáveis correlacionadas à capacidade 
tributária do município, à capacidade estatal e aos fatores políticos. Assim sendo, foram utilizadas as variáveis que se encontram na Tabela 2.

A Tabela 2 apresenta a descrição e a fonte de todas as variáveis utilizadas neste estudo. A escolha desse período justifica-se pelo fato de a pesquisa ter sido realizada nos anos de 2015 e 2016.

As variáveis resultado orçamentário, receita corrente, despesa corrente, despesa corrente per capita, receita corrente per capita e transferências voluntárias, que compuseram a categoria capacidade tributária e fiscal, foram escolhidas por se referirem às condições financeiras dos municípios e, por conseguinte, às suas possibilidades de fazer face às demandas educacionais. Nesse sentido, vários trabalhos acadêmicos (Araújo, 2012; Araujo, 2013; Arretche, 2010; Soares e Melo, 2016) vêm apontando que a baixa capacidade tributária dos entes municipais é um dos fatores que incidem sobre as condições e modos de oferta educacional, podendo ter efeito, inclusive, sobre a redução das desigualdades.

A variável existência de Secretaria de Educação foi utilizada por se entender com Pinto (2014) que o fato de o município possuir uma Secretaria de Educação exclusiva tenderia a contribuir para a autonomia do setor educacional diante de outros setores do Estado, o que poderia levar à formulação de políticas e modos de oferta de educação também mais independentes.

Já a escolha das variáveis gasto com educação e FUNDEB se justifica por elas estarem relacionadas diretamente ao financiamento educacional e, por isso, poderem ter relação com as lógicas privilegiadas pelos municípios em termos de oferta. Nessa direção, a literatura vem apontando o peso que os gastos com educação têm sobre as finanças dos municípios, bem como os efeitos do FUNDEB sobre as condições de oferta educacional, especialmente creches (Loyola, 2017; Araújo, 2012).

Todas essas variáveis foram expressas em valores ou quantidades anuais para cada município. Foi feito então um teste comparando os municípios que apresentam ou não

Tabela 2 - Descrição de variáveis utilizadas no trabalho.

\begin{tabular}{|c|c|c|c|}
\hline Categoria & Variável & Fonte & Ano \\
\hline \multirow{6}{*}{$\begin{array}{l}\text { Capacidade } \\
\text { tributária e fiscal }\end{array}$} & Resultado orçamentário & SICONFI/STN & 2014 \\
\hline & Receita corrente & SICONFI/STN & 2014 \\
\hline & Despesa corrente & SICONFI/STN & 2014 \\
\hline & Despesa corrente per capita & SICONFI/STN & 2014 \\
\hline & Receita corrente per capita & SICONFI/STN & 2014 \\
\hline & Transferências voluntárias & FINBRA & 2014 \\
\hline Capacidade estatal & Existência de Secretaria de educação & MUNIC & 2014 \\
\hline \multirow{3}{*}{$\begin{array}{l}\text { Financiamento } \\
\text { educacional }\end{array}$} & Gasto com educação & FINBRA & 2014 \\
\hline & Gasto com Educação per capita & FINBRA & 2014 \\
\hline & FUNDEB & SNT & 2014 \\
\hline
\end{tabular}

Fonte: organizada, pelos autores, com dados do estudo. 
oferta no terceiro setor para cada uma delas. Por não seguirem distribuição normal, foi necessário utilizar o teste não paramétrico de Wilcoxon. O nível de significância utilizado em todos os testes foi de 5\%. Os resultados dos testes são apresentados na Tabela 3.

Os testes estatísticos evidenciaram que as variáveis i) resultado orçamentário, ii) despesa corrente, iii) receita corrente e iv) gasto com educação apresentaram uma diferença significativa no que diz respeito ao modo de oferta privilegiado pelas municipalidades. Isso significa dizer que capacidade tributária e fiscal do município é, de fato, um fator que influencia positivamente a opção dos gestores por dispersarem a oferta de vagas em creche para atores situados fora do aparelho de Estado. Os coeficientes associados ao comportamento financeiro municipal mantiveram-se positivos e significantes em todos testes, com exceção das transferências discricionárias voluntárias e das transferências provenientes do FUNDEB que não mostraram associação significativa.

No que tange à não relevância de recursos do FUNDEB e às transferências voluntárias para explicar escolha de modos de oferta, cabe sublinhar que esses resultados devem ser examinados com cautela, pois essas mesmas variáveis já foram consideradas significativas em termos de redução de desigualdade de receita de municípios, como apontado por Arretche (2010). De todo modo, o fator orçamentário foi aquele que melhor explicou, estatisticamente, a escolha dos gestores municipais.

Tendo em vista que o estudo privilegiou a "permeabilidade" estatal como categoria teórico-analítica para examinar possíveis razões explicativas para lógicas

Tabela 3 - Descrição de resultados encontrados.

\begin{tabular}{|c|c|c|}
\hline Variável & $\begin{array}{l}\text { Medida de } \\
\text { Diferença }\end{array}$ & Conclusão \\
\hline Resultado orçamentário & Sim & $\begin{array}{l}\text { Municípios com resultados orçamentários } \\
\text { deficitários tendem a utilizar mais o } \\
\text { terceiro setor. }\end{array}$ \\
\hline Receita corrente & Sim & $\begin{array}{l}\text { Municípios com maior receita corrente } \\
\text { tendem a utilizar mais o terceiro setor. }\end{array}$ \\
\hline Despesa corrente & Sim & $\begin{array}{l}\text { Municípios com maior despesa corrente } \\
\text { tendem a utilizar mais o terceiro setor. }\end{array}$ \\
\hline Despesa corrente per capita & Não & - \\
\hline Receita corrente per capita & Não & - \\
\hline Transferências voluntárias & Não & - \\
\hline Existência de Secretaria de Educação & Não & - \\
\hline Gasto com educação & Sim & $\begin{array}{l}\text { Municípios com maior gasto de educação } \\
\text { tendem a utilizar mais o terceiro setor. }\end{array}$ \\
\hline FUNDEB & Não & - \\
\hline
\end{tabular}

Fonte: elaborada, pelos autores, com dados do estudo. 
explicitadas pelos municípios, em termos de oferta, exatamente porque ela teria potencial para dar conta de perscrutar outros fatores envolvidos no processo de escolha, para além daqueles de natureza financeira, a pesquisa elegeu, também, a variável "ideologia partidária" na delimitação do seu desenho (Tabela $4^{5}$ ).

No caso da variável ideologia partidária, tinha-se como hipótese que as municipalidades dirigidas por gestores alinhados à esquerda do espectro político brasileiro tenderiam a explicitar nos seus PMEs opções de oferta via Estado e aquelas vinculadas à direita optariam por uma lógica voltada ao terceiro setor. Para a testagem dessa hipótese, foram considerados apenas os municípios capitais. Essa opção metodológica está alicerçada na literatura que vem apontando que as ideologias partidárias não têm se mostrado influentes em municípios pequenos (Gerigk, 2016).

Já a hipótese de trabalho relacionada à ideologia partidária foi construída a partir de evidências trazidas pela literatura especializada (Figueiredo e Limongi, 1999; Zucco Junior, 2009; Madeira e Tarouco, 2011), que afirma que no Brasil “há uma direita, um centro e uma esquerda. Além disso, há uma centro-direita e uma centro-esquerda" (Figueiredo e Limongi, 1999, p. 93), em que pese os discursos difundidos pelo senso comum sobre a fragilidade da estrutura partidária brasileira. Levou-se ainda em conta outra contribuição da literatura que tem afirmado que "esquerda e direita estão claramente associadas a maior e menor intervenção do Estado na economia" (Zucco Junior, 2009, p. 1), aproximando-se, a partir dos anos de 1990, de temas mais delimitados "como privatização e desregulamentação da economia” (Madeira e Tarouco, 2011, p. 175).

Para o teste, foi identificado o partido dos prefeitos das capitais, em 2012, e qual a sua ideologia partidária, a partir das estimativas de posicionamento ideológico dos principais partidos brasileiros realizadas por Zucco Junior (2009) e apresentadas na Figura 2.

A fim de verificar se a posição ideológica tinha alguma influência no modo de oferta de creches do município, ou seja, partido de direita privilegiar o terceiro setor e partidos de esquerda escolher a oferta direta, via Estado, foi realizado um teste do qui-quadrado de independência entre as duas variáveis, uma vez que as duas variáveis analisadas são categóricas (Gráfico 1).

Observa-se, pelas barras do Gráfico 1, que as prefeituras cujos prefeitos são de partidos alinhados com a direita possuem proporção maior de intenção de oferta pelo terceiro setor, $87 \%$. Enquanto para o caso da esquerda esse percentual é de $60 \%$. A princípio, a diferença entre as proporções de 60 e $87 \%$ entre esquerda e

Tabela 4 - Descrição da variável ideologia partidária utilizada no trabalho.

\begin{tabular}{l|c|c|c}
\hline Categoria & Variável & Fonte & Ano \\
\hline Fator político & Ideologia partidária & Tribunal Superior Eleitoral & 2012 \\
\hline
\end{tabular}

5 A variável ideologia partidária foi organizada por dados disponíveis no Tribunal Superior Eleitoral, para o ano de 2012. A escolha desse período justifica-se pelo fato de a pesquisa ter sido realizada nos anos de 2015 e 2016. 
direita é expressiva, mas cabe lembrar que, do ponto de vista estatístico, o número de capitais não é muito grande, 25 , sendo que não contamos com a informação de duas delas (Cuiabá e Rio de Janeiro).

A conclusão do teste foi de não rejeição da hipótese nula de independência entre as variáveis a $5 \%$ de significância, o que significa que a ideologia partidária do prefeito não parece estar associada ao modo de oferta dessa etapa educacional.

\begin{tabular}{|l|llllllllllllll|}
\hline 1990 & PC do B & PT & PCB & PSB & PDT & PSDB & PMDB & PTB & PL & $\begin{array}{c}\text { PDC } \\
\text { PRN }\end{array}$ & PFL & PDS \\
\hline 1993 & PC do B & $\begin{array}{c}\text { PT } \\
\text { PSTU }\end{array}$ & PSB & PPS & PDT & PSDB & PMDB & PP & PTB & $\begin{array}{c}\text { PL } \\
\text { PFL }\end{array}$ & PPR & PRN \\
\hline 1997 & PC do B & PT & PSB & PPS & PDT & PMDB & PSDB & PTB & PL & PFL & PPB & \\
\hline 2001 & PC do B & PT & PSB & PDT & PPS & $\begin{array}{c}\text { PMDB } \\
\text { PSDB }\end{array}$ & PL & PTB & PFL & PPB & \\
\hline 2005 & PC do B & $\begin{array}{c}\text { PSB } \\
\text { PT }\end{array}$ & PPS & PDT & $\begin{array}{c}\text { PMDB } \\
\text { PSDB }\end{array}$ & $\begin{array}{c}\text { PTB } \\
\text { PL }\end{array}$ & PFL & PP & \\
\hline 2009 & PSOL & PC do B & $\begin{array}{c}\text { PSB } \\
\text { PT }\end{array}$ & PDT & PV & PPS & $\begin{array}{c}\text { PMDB } \\
\text { PSDB }\end{array}$ & PTB & PR & PP & DEM \\
\hline
\end{tabular}

Figura 2 - Posição ideológica dos partidos, estimada por Zucco Junior (2009).

Fonte: Zucco Junior (2009).

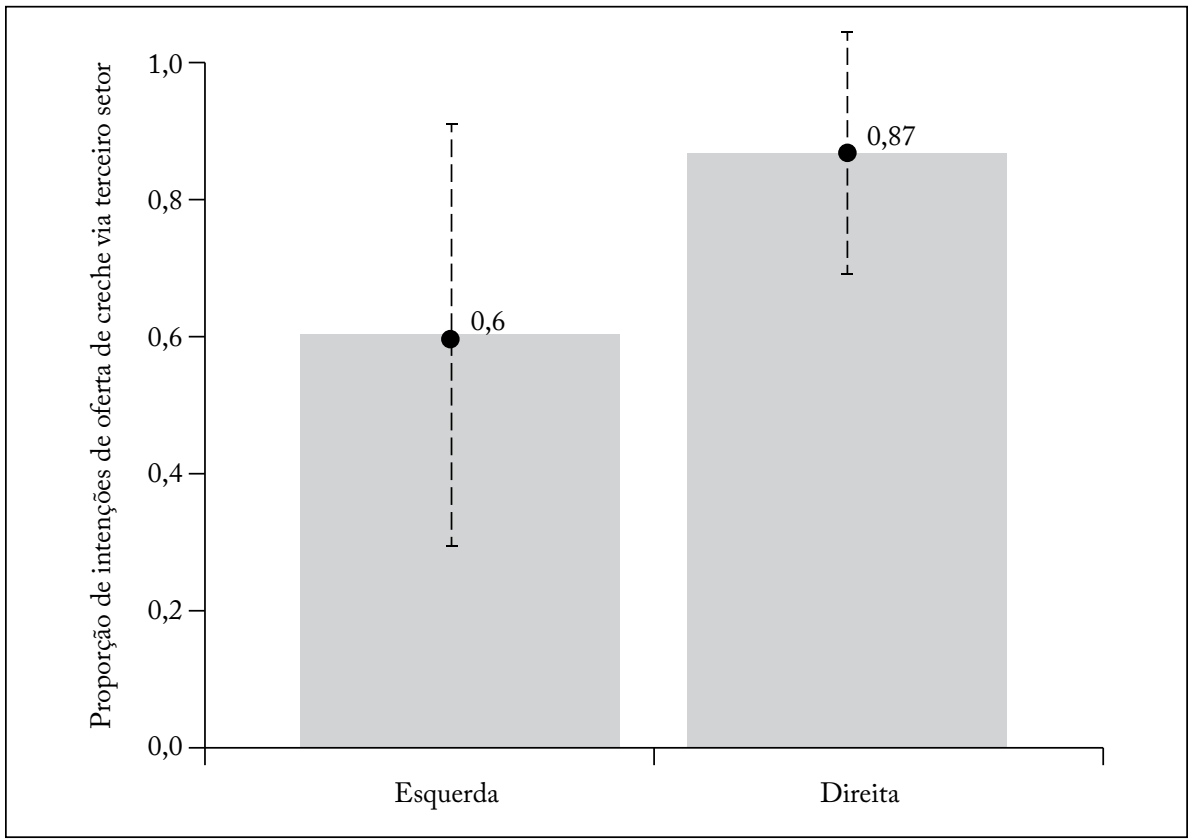

Gráfico 1 - Proporção de intenção de oferta de creches via terceiro setor, explicitadas em Planos Municipais de Educação, segundo ideologia do partido do prefeito.

Fonte: elaborado, pelos autores, com dados do estudo. 


\section{CONSIDERAÇÕES FINAIS}

Objetiva-se, nesta seção, recuperar, nos resultados, os aspectos que sobressaíram no conjunto dos dados analisados, sublinhando que não se buscou estabelecer generalizações empíricas por meio da amostra probabilística utilizada, mas, tão somente, tentar propor algumas implicações teóricas ou levantar algumas hipóteses para outros contextos a serem investigados.

Nesse sentido, a pesquisa apontou a presença de uma significativa interação entre Estado e instituições do terceiro setor na oferta da educação infantil, etapa creche, explicitada nos PMEs para a década 2014-2024. Embora um dos achados de pesquisa seja que os documentos seguiram lógicas distintas de estruturação, descumprindo a lei n. 13.005/2014, que dispõe sobre o necessário alinhamento dos entes federados ao PNE, no tocante às diretrizes, às metas e às estratégias, um traço comum entre eles é a opção pela oferta da primeira etapa da educação infantil via dispersão para outros locais de governança. O mapeamento da oferta, via amostra, dá conta de que apenas dois municípios explicitaram a intenção de restringir a interação com a sociedade civil na oferta da educação infantil, até 2024, embora o façam atualmente: Belém (PA) e Vitória (ES).

Em sentido oposto, alguns municípios explicitaram em seus documentos que tendem a fortalecer a dispersão da oferta para a sociedade civil organizada, por meio de institutos jurídicos distintos, como o antigo convênio, mas também com OSs. A amostra permitiu observar que há municípios com lógicas de parceria mais consolidadas em seus planos decenais que outros.

Utilizando o conceito de "permeabilidade" estatal, o trabalho buscou investigar, ainda, possíveis fatores explicativos para a opção de oferta de vagas em creche por atores situados fora do aparelho de Estado. A ferramenta conceitual mostrou-se profícua por permitir captar outras variáveis que pudessem dar conta de explicar os modos de oferta privilegiados, extrapolando o argumento clássico de natureza tributário-fiscal.

Tanto os testes estatísticos realizados como a revisão da literatura empreendida sugerem que variáveis relacionadas ao comportamento orçamentário dos entes municipais, como resultado fiscal, receitas e despesas correntes, gastos com educação, têm correlação positiva com a escolha pelo modo de oferta via terceiro setor, o que confirma a hipótese clássica relacionada ao financiamento educacional.

Já variáveis voltadas à capacidade estatal, à ideologia partidária, ao FUNDEB e às transferências voluntárias não se mostraram significativas para explicar a lógica explicitada nos PMEs.

Por fim, não parece descabido afirmar que a permeabilidade do Estado em relação aos atores do terceiro setor expressa, por um lado, uma tendência que pode ser observada em todas as regiões e, por outro, que essa lógica de oferta de educação infantil parece se constituir mesmo em política de Estado, tendo em vista, sobretudo, que se encontra expressa em PMEs para uma década (2014-2024).

\section{REFERÊNCIAS}

Araújo, R.L.S. Desvendando o perfil dos gastos educacionais dos municípios brasileiros. Educação ES Sociedade, Campinas, v.33, n.121, p.1215-1233, dez. 2012. 
Araujo, G.C. Federalismo e políticas educacionais no Brasil: equalização e atuação do empresariado como projetos em disputa para a regulamentação do regime de colaboração. Educação E' Sociedade, Campinas, v.34, n.124, p.787-802, set. 2013.

Arelaro, L.G. A não-transparência nas relações público-privadas: o caso das creches conveniadas. In: Adriño, T.; Peroni, V. (Org.). Público e Privado na Educação: novos elementos para o debate. São Paulo: Xamã, 2008. p. 53-66.

Arretche, M. Mitos da descentralização: mais democracia e eficiência nas políticas públicas? Revista Brasileira de Ciências Sociais, São Paulo, v. 11, n. 31, jun. 1996.

.Federalismo e igualdade territorial: uma contradição em termos? Dados: Revista de Ciências Sociais, Rio de Janeiro, v.53, n.3, p.587-620, 2010.

Bardin, L. Análise de conteúdo. Lisboa: Edições 70, 2009.

Belém. Lei n. 9.129, de 24 de junho de 2015. Aprova o Plano Municipal de Educação. Diário Oficial do Município. Belém, 2015.

Belo Horizonte. Lei n. 10.917, de 14 de março de 2016. Aprova o Plano Municipal de Belo Horizonte. Diário Oficial do Município, Belo Horizonte, 2016.

Brasil. Lei n. 9.637, de 15 de maio de 1998. Dispõe sobre a qualificação de entidades como organizações sociais, a criação do Programa Nacional de Publicização, a extinção dos órgãos e entidades que menciona e a absorção de suas atividades por organizações sociais, e dá outras providências. Diário Oficial da União, Brasília, DF, 1998.

Brasil. Lei n. 9.790, de 23 de março de 1999. Dispõe sobre a qualificação de pessoas jurídicas de direito privado, sem fins lucrativos, como Organizações da Sociedade Civil de Interesse Público, institui e disciplina o Termo de Parceria, e dá outras providências. Diário Oficial da União, Brasília, DF, 1999.

.Lei n. 13.005, de 25 de junho de 2014. Aprova o Plano Nacional de Educação PNE e dá outras providências. Diário Oficial da União, Brasília, 2014.

CAmpos, M.M. A regulação da educação infantil. In: Brasıl. Ministério da Educação e do Desporto. Subsídios para credenciamento e funcionamento de instituiçóes de educação infantil.v. II. Brasília: MEC, 1998.

.; Coelho, R. C.; Cruz, S. V. Consulta sobre a qualidade da educação infantil: Relatório Técnico Final. Textos FCC. São Paulo: Fundação Carlos Chagas, 2006.

Cardoso, F.H. Aspectos políticos do planejamento. In: Lafer, B.M. Planejamento no Brasil. São Paulo: Editora Perspectiva, 1975.

Cury, C.R.J. A educação infantil como direito. In: Brasil. Ministério da Educação e do Desporto. Subsídios para credenciamento e funcionamento de instituiçóes de educação infantil. v. II. Brasília: MEC, 1998.

. Direito à educação: direito à igualdade, direito à diferença. Cadernos de Pesquisa, São Paulo, n.116, p.245-262, jul. 2002.

. A educação básica como direito. Cadernos de Pesquisa, São Paulo, v.38, n.134, p.293-303, maio-ago. 2008.

Di Pietro, M.S.Z. Parcerias na administração pública: concessão. permissão, franquia, terceirização, parceria público-privada e outras formas. 10. ed. São Paulo: Atlas, 2015. 
Dinız, E. Governabilidade, governance e reforma do Estado: considerações sobre o novo paradigma. Revista do Serviço Público, Brasília, ano 47, v.120, n.2, maio-ago. 1996. Distrito Federal. Lei n. 5.499, de 14 de julho de 2015. Aprova o Plano Distrital de Educação - PDE e dá outras providências. Diário Oficial do Distrito Federal, Brasilia, 2015. Draibe, S. M. O welfare State no Brasil. Características e Perspectivas. Cadernos de Pesquisa n ${ }^{\circ}$ 08. Campinas: NEPP/UNICAMP, 1993.

Fernandes, F. A Constituição inacabada: vias históricas esignificado. Estação Liberdade, 1989. Figueiredo, A.; Limongi, F. Executivo e Legislativo na Nova Ordem Constitucional. Rio de Janeiro: Ed. FGV, 1999.

Gerigk, W. Política nos pequenos municípios brasileiros: uma análise de seus efeitos sobre o processo decisório, as políticas fiscais e os investimentos públicos. Tese (Doutorado em Políticas Públicas) - Universidade Federal do Paraná, Curitiba, 2016.

Instituto Brasileiro de Geografia e Estatística - IBGE. Pesquisa Nacional por Amostra de Domicílios. Aspectos dos cuidados das crianças de menos de 4 anos de idade: 2015. Rio de Janeiro: IBGE, 2017.

Kooiman, J. Governing as Governance. London: SAGE Publications, 2003.

Loyola, P. Autonomia municipal e interdependência federativa: uma análise sobre as mudanças ocorridas no acesso e gastos em educação no Brasil (2000-2014). Educação E Sociedade, Campinas, v.38, n.140, p.767-790, 2017.

Madeira, R.M.; Tarouco, G. S. Esquerda e direita no Brasil: uma análise conceitual. Revista Pós Ciências Sociais, v.8, n.15, p.171-186, jan.-jun. 2011.

Marques, E.C. Redes sociais e instituições na construção do Estado e da sua permeabilidade. Revista Brasileira de Ciências Sociais, São Paulo, v.14, n.41, p.45-67, out. 1999.

. Estado e Redes sociais: permeabilidade e coesão nas políticas urbanas no Rio de Janeiro. Rio de Janeiro: Revan; São Paulo: Fapesp, 2000.

. Redes sociais e poder no Estado brasileiro: aprendizados a partir de políticas urbanas. Revista Brasileira de Ciências Sociais, São Paulo, v. 21, n. 60, p. 15-41, fev. 2006. Massardier, G. Redes de políticas públicas. In: Saravia, E.; Ferrarezi, E. (Orgs.) Políticas públicas: coletânea. Brasília/DF: ENAP, 2006. v. II. p.167-185.

Melo, M.M. Governance e reforma do Estado: o paradigma agente x principal. Revista do Serviço Público, ano 47, v.120, n.1, p.67-82, jan.-abr. 1996.

Ministério de Administração e Reforma do Estado - MARE. Plano Diretor da Reforma Administrativa do Aparelho do Estado. Brasília: MARE, 1995.

Oliveira, R.P.; Adriño, T. Os 25 anos da Constituição de 1988: reflexões sobre o direito à educação de qualidade. In: Leite, Y.; Militão, S.; Lima, V. Políticas Educacionais e Qualidade da Educą̧ão Pública. Curitiba: CRV,2013. p. 29-42.

Pinto, J.M.R. Federalismo, descentralização e planejamento da educação: desafios aos municípios. Cadernos de Pesquisa, São Paulo, v.44, n.153, p.624-644, jul.-set. 2014. Rhodes, R.A.W. The New Governance: Governing without Government. Political Studies, v.44, n.4, p. 652-667, 1996. 
São Paulo. Proposta de Substitutivo ao PL n. 415/2012 - Versão Preliminar. Diário Oficial do Município. São Paulo, 2014.

. Lei n. 16.271, de 17 de setembro de 2015. Aprova o Plano Municipal de São Paulo. Diário Oficial do Município, São Paulo, 2015.

Soares, M.M.; Melo, B.G. Condicionantes políticos e técnicos das transferências voluntárias da União aos municípios brasileiros. Revista de Administração Pública, Rio de Janeiro, v.50, n.4, p.539-562, ago. 2016.

TRIPODI, M.R.F. Locais de governança na educação infantil — Estudo exploratório dos modos de oferta explicitados nos Planos Municipais de Educação 2014-2024. Relatório Final de Pesquisa. São Paulo: FAPESP/USP, 2016.

Vitória. Lei n. 8.829, de 24 de junho de 2015. Aprova o Plano Municipal de Vitória. Diário Oficial do Município, Vitória, 2015.

Zucco Junion, C. Esquerda, direita e governo: a ideologia dos partidos políticos brasileiros. Seminário Legislator Views of Brazilian Governance. Oxford: Universidade de Oxford, setembro de 2009. p. 1-18.

\section{SOBRE OS AUTORES}

Zara Figueiredo Tripodi é doutora em educação pela Universidade de São Paulo (USP). Professora da Universidade Federal de Ouro Preto (UFOP). E-mail: zaratripodi@gmail.com

Victor Maia Senna Delgado é doutor em demografia pela Universidade Federal de Minas Gerais (UFMG). Professor da Universidade Federal de Ouro Preto (UFOP).

E-mail: vic_senn@yahoo.com.br

Érica Castilho Rodrigues é doutora em estatística pela Universidade Federal de Minas Gerais (UFMG). Professora da Universidade Federal de Ouro Preto (UFOP).

E-mail: ericacastirodrigues@gmail.com

Recebido em 19 de outubro de 2017 Aprovado em 8 de maio de 2018 